\title{
Flexible scheduling, degradation of job quality and barriers to collective voice
}

Alex $J$ Wood

\begin{abstract}
This article examines the operation of flexible scheduling in practice through a case study of a large retail firm in the United Kingdom. It includes analysis of 39 semi-structured interviews, participant observation of shop floor work and non-participant observation of union organising as well as analysis of key documents. The findings highlight the high level of generalised temporal flexibility across employment statuses. This temporal flexibility enables firm flexibility without necessitating a reliance upon contingent workers. Temporal flexibility is found to entail manager-control of flexible scheduling and is shown to be damaging to perceptions of job quality as it acts as a barrier to work-life balance. Union presence and collective bargaining at the firm are found to be ineffective at influencing flexible scheduling so as to improve job quality. This ineffectiveness can be explained by the union operating in an employer-dominated industrial relations environment in which its associational power is unable to compensate for a lack of institutional and structural economic power.
\end{abstract}

\section{Keywords}

contingent, flexibility, job quality, partnership, retail, scheduling, trade union, voice, working time 


\section{Introduction}

There is growing concern about the potential repercussions surrounding flexible scheduling, especially practices which enable workplace managers to vary 'the number and timing of employees' work hours' (Lambert, 2008: 1207). For example, in the United Kingdom (UK), there has been a great deal of public discussion surrounding 'zero hours contracts' (ZHCs) an 'employment contract in which the employer does not guarantee the individual any work' (BIS, 2013: 7). In particular, there is concern that such flexible scheduling practices may be detrimental to work-life balance (WLB). Yet other research suggests that flexible scheduling such as ZHCs can be positive for some workers (CIPD, 2013, 2015; Pennycook et al., 2013). This article examines this inconsistency through an in-depth investigation of workers' experience of flexible scheduling at a large UK retailer.

The article begins with a review of the extant literature on flexible scheduling and its impact on job quality. In Continental Europe trade unions have been found to positively affect flexible scheduling with regards to job quality. Therefore, the potential for trade unions similarly to improve flexible scheduling in the UK is also considered. The article proceeds to investigate empirically UK workers' experience of flexible scheduling in practice, the consequences for job quality, and how flexible scheduling is affected by the presence of a trade union and collective bargaining. These findings are then discussed with regards to the extant literature and implications for future research and policy are elucidated.

\section{Flexibility and the firm}

The pursuit of greater flexibility by firms has been central to many influential accounts of the changing nature of employment. Most accounts have focused upon the use of contingent workers to increase a firm's ability to respond to changing market conditions and thus lower labour costs (Atkinson, 1984; Matusik and Hill, 1998). In these accounts contingent work is 
understood as facilitating numerical flexibility. Atkinson (1984) differentiates between three groups of employees, the first group is made up of core workers whose role, skills, or experience make them relatively indispensable. These workers are conceptualised as providing functional flexibility. The model additionally identifies two peripheral groups. The 'first peripheral group' consists of full-time workers who provide numerical flexibility through being exposed to the external labour market. Exposure to the external labour market translates into these workers having few employment protections and experiencing job insecurity, resulting in a high turnover rate. The 'second peripheral group' alternatively provides functional and numerical flexibility. The realisation of simultaneous functional and numerical flexibility is argued to be achieved through atypical employment statuses, such as short-term and part-time contracts. Beyond the flexibility of the firm's workforce further flexibility is also held to be provided by greater emphasises upon agency and temporary workers, self-employment, outsourcing and subcontracting (Atkinson, 1984).

Ackroyd and Procter (1998) provide an elaboration of Atkinson's model, which they term the 'new flexible firm.' According to this model flexibility is not achieved through a highly trained and secure core of functionally flexible workers. Instead it is attained via organising a semi-skilled workforce into numerically flexible semi-autonomous cells or segments. These cells provide functional flexibility through on the job training for specific tasks. They also provide numerical flexibility by acting as independent cost centres, so that managers can assess the costs and benefits of specific activities and dispense with them, along with the corresponding work group, when deemed insufficiently profitable.

Both the flexible firm and the new flexible firm models largely ignore the importance of temporal flexibility. Yet the findings of Rubery et al. (2005) suggest that temporal flexibility may represent a new regulation of working time which has spread far beyond contingent work. Lambert (2008) demonstrates that the achievement of temporal flexibility 
through flexible scheduling has arisen, in the United States at least, because employers are increasingly unwilling to pay for labour which exceeds demand on an hourly or daily basis. Staffing outlay budgets are tightly linked to customer demand and frontline managers are expected to closely enforce these budgets.

Schedule flexibility has, however, been understood in contradictory ways by different researchers. For example, Holman (2013a) uses it to mean an employee's ability to choose their own hours, whereas Lambert (2008) uses it to refer to unpredictable schedules which are imposed upon the worker. This confusion is reflected in the public discussion of schedule flexibility, where it is often claimed to benefit both employers (by matching labour supply to demand, reducing labour costs and enabling a more efficient service), and employees (by improving WLB) (see for example, BIS, 2013: 4). Henly et al. (2006: 619) highlight that there is an important conceptual distinction to be made between, manager-controlled flexible scheduling (MCFS) and worker-controlled flexible scheduling (WCFS).

Usually, MCFS is seen as principally beneficial to employers and WCFS for employees. Research suggests that despite employer claims to the contrary flexible scheduling can not be both manager-controlled and worker-controlled. For example, Hyman et al. (2005: 719-720) find that: "“Flexible" working time patterns were only flexible for the employers and actually undermined workers' own coping arrangements.' Lambert et al. (2012: 304) state that 'the zero-sum game created among workers when employers apply strict limits to total labour hours means that control granted to one employee tends to lessen control enjoyed by co-workers.' However, in practice, differentiating MCFS and WCFS is not always straightforward and is context-dependent, with the same formal employment status operating differently for different workers. The first aim of this article is to provide an indepth exploration of temporal flexibility and the degree to which flexible scheduling is manager or worker controlled. 


\section{Flexible scheduling and job quality}

The unpredictability and variability of working time generated by MCFS can be highly damaging to WLB (Chung et al., 2007; Goudswaard et al., 2012; Riedmann et al., 2010; Rubery et al., 2005). Specifically, short notice changes to working times have been found to interfere with workers' ability to manage personal responsibilities (Zeytinoglu et al., 2004), and disrupt family and social activities (Fagan and Burchell, 2002; Henly and Lambert, 2005; Henly et al., 2006; Lambert et al., 2012; Rubery et al., 2005). This impact upon WLB has led schedule flexibility to be highlighted as an important element of job quality (Carré et al., 2010; Findlay et al., 2013; Holman, 2013a; Kalleberg 2011).

However, research into ZHCs, in the UK by the CIPD $(2013 ; 2015)$ and Pennycook et al. (2013) suggests that MCFS may not actually be detrimental to all workers' WLB, especially those who have few other time-bound commitments, such as students or those transitioning to retirement. As explained above, the boundary between MCFS and WCFS is in practice not clear cut. Riedmann et al. (2010: 14) point out that the degree to which forms of flexible scheduling are positive for WLB depends to a large degree upon 'the way that such work is practised in the establishments.' The second aim of this article is to ascertain how flexible scheduling in practice affects perceptions of job quality, principally in terms of WLB.

\section{Schedule flexibility, control and trade unions}

There is evidence that trade unions can have a positive effect upon the manner in which flexible scheduling is practiced and improve job quality (Carré et al., 2010; Holman, 2013b; Goudswaard et al., 2012; Kalleberg, 2011). In fact, employee control over working hours is highlighted by the job quality literature as a component of 'good jobs' (Holman, 2013; Kelleberg; 2011), with control of working time being what distinguishes WCFS (which can 
be positive for WLB from MCFS).

For most of the twentieth century trade unions in Europe exercised a powerful constraint over working time through sectoral level collective bargaining. This established the notion of a 'standard working week' and ensured that the great bulk of employment was 'fulltime,' with 'part-time' work being resisted by trade unions in most European countries. When part-time employment become more significant later in the century it was incorporated into the existing systems of legal and collective regulation. For Continental Europe, although not the UK, there was, and continues to be, substantial legal supports for the institutional constraint over managerial power (Gregory and Milner, 2009; Rubery et al., 2005). Indeed, in Continental Europe unions have been found to have a positive effect on job quality through constraining MCFS (Carré et al., 2010; Holman, 2013b; Goudswaard et al., 2012). In part this likely to be due to legal institutional supports which facilitate both involvement in decisionmaking and bargaining power (Hoque et al., 2014; Rubery et al., 2005).

In the UK, where legal support is lacking, and sectoral agreements were in rapid decline from the 1970s, trade unions could only exercise constraints insofar as they had effective recognition and influence at the workplace (Rubery et al., 2005). Furthermore, Hoque et al. (2014) point out that positive voice effects can only emerge if workers' voice is actually heard by managers and if they are in turn 'willing (or compelled) to respond constructively. This... is likely to depend on the union's scope for involvement in decisionmaking and on its bargaining strength.' However, private sector unions and collective bargaining in the UK have suffered rapid decline (Brown et al., 2009), with private sector collective bargaining coverage now standing at just 17\% of the workforce (BIS, 2014: 31). Moreover, this bargaining tends to be at the company level which in competitive product markets leaves unions with limited bargaining leverage (Katz, 1993; Wright and Brown, 2013). 
In addition to low levels of density and collective bargaining coverage UK employment relations have been marked by a process of 'procedural individualisation,' whereby collective mechanisms for determining terms and conditions of employment are weakened or abolished (Brown et al., 2000). Procedural individualisation can, arguably, be equated with the de facto derecognition of unions for collective bargaining purposes. These factors suggest that UK private sector unions not only lack institutional supports, which Gumbrell-McCormick and Hyman (2013) term ‘institutional power,' but also 'associational power.' Associational power being the power which accrues to workers through organisation into collective bodies such as trade unions and political parties (Wright, 2000). Furthermore, Wright and Brown (2013) argue that the internationalisation of product markets and corporate ownership, the intensification of competition, and greater fragmentation of labour and product markets have all undermined, what Wright (2000) terms, union's 'structural economic power.' Structural economic power being dependent upon factors such as high-skill levels and tight labour markets.

The ability of unions to mobilise collective voice is also dependent upon having workplace trade union representatives (union reps) who are able to act as a conduit. There is evidence that the collective voice function of union reps in the UK finance sector does indeed improve worker perceptions of job quality (Hoque et al., 2014). But the collapse of union rep organisation over the past thirty years suggests this may not be widespread (Darlington, 2010). Lacking the legal supports of their Continental counter-parts, from the 1990s onwards UK unions have been increasingly obliged to adopt a 'partnership approach.' Arguably, this further diminished unions' ability to effectively pursue the interests of their members (Badigannavar and Kelly, 2011). Kelly (2004) finds that partnership outcomes are dependent upon bargaining power. Partnership without bargaining strength is, therefore, unlikely to substantially increase worker influence over schedules. The third aim of this article is to 
investigate the ability of a trade union to improve perceptions manager-controlled flexible scheduling and thus job quality.

\section{Research strategy and methods}

Owing to the complexity of both the mechanisms by which schedule flexibility is achieved and the forms of influence exerted upon them by trade unions, an in-depth ethnographic case study approach was deemed most appropriate. The focus on employee perceptions and experiences of flexible scheduling in practise necessitated an emphasis upon the views of workers and, in particular, union reps.

The case has been anonymised and will be referred to as ShopPLC, a large retailer with a leading market position, and one of the largest private sector employers in the UK. After considering derecognition in the late 1990s, ShopPLC signed a formal company level 'partnership' collective agreement with the recognised union. This agreement is often highlighted as a successful example of the partnership approach. Union density was above $60 \%$ nationally (four times the sector average of 15\%) and membership had been growing at a fast rate. The research was not covert and informed consent was given by all of the primary informants.

Edwards (2014) stresses the importance in case study research of understanding the unit of analysis. In this research the unit of analysis was the firm (ShopPLC), therefore it was appropriate to collect data from multiple ShopPLC workplaces. With this in mind, interviews were conducted with 19 workers at four ShopPLC London hypermarkets, all of but one of whom were union members and nine were union reps. Observation of union organising was undertaken at two of these stores and an additional two stores. Two months of participant observation, i.e. working as a shelf-stacker on an 8.5 hours a week contract was also undertaken at a separate hypermarket. Interviews were also undertaken with 10 ShopPLC 
union reps, each from a different store, who were on secondment to the union for a number of months in order to develop their recruitment and organising skills. These 10 union reps provided the initial means of accessing ShopPLC as their secondment meant that the union could introduce them to me at their training events. Their secondment also provided them with much greater flexibility to engage in in-depth interviews than would normally be the case. These interviews usually lasted well over an hour. As part of their secondment these reps were also visiting a large number of stores in order to practice their recruitment skills and were willing for me to accompany and observe them. In total five days of union organising, three union team meetings, and a branch meeting were observed and recorded. During these store visits they would also introduce me to workers so that I could carry out interviews. Six regional union officials were additionally interviewed and notes taken from meetings with two senior leadership officials.

In total, the interviews comprised 39 semi-structured interviews with 35 informants. The informants included 29 non-managerial hourly paid employees (of which 19 were union reps) and 6 union officials. The job roles of these worker informants were: checkout operators (10); stock replenishment and price assistants (4); general shop floor assistants (8) - mainly stacking shelves and operating checkouts when required; pharmacy, optician, photo lab and customer service assistants (5); and online delivery drivers (2). The informants were drawn from across ages and were of a gender mix of approximately 50-50.

As is standard practice in qualitative research, the generation of this sample was not guided by any attempt to make it representative but rather to reach 'theoretical saturation' (Bryman, 2008). Theoretical saturation is reached when the collection of new data ceases to further elaborate the understanding of a phenomenon, therefore the sampling is driven, within practical considerations, by theoretical assumptions as to what data will further elucidate the findings. 
The fact that there were no discernible cross-workplace differences in the results reported below significantly increases the robustness of case study findings. However, in order to limit the potential for regional labour market differences to impact upon the findings, the fieldwork was confined to the London area. Data collection took place between June 2012 and June 2013. This was a time of labour market slack with the national and London unemployment rate being above $8 \%$ (ONS, 2015). Obviously, this raises the question of generalisability beyond this specific spatial and temporal context. For example, in tighter labour markets the practices documented below may not be possible as workers may opt for alternative employment.

Towards the end of the research period it was deemed necessary to gain a deeper insight into the lived experience of flexible scheduling than had so far been achieved from studying it solely as a removed outside researcher. Sallaz (2015: 9) shows the value of researchers experiencing a workplace 'directly with their own voices, bodies, and moral sensibilities.' Such research has played an important role in the sociology of work, classic studies such as Roy (1952), Burawoy (1979) and Glucksmann (aka Cavendish) (2009) exemplifying the richness which can be provided by this approach. With this in mind, two months of participant observation at the Mulling Point hypermarket (a pseudonym) in North London was undertaken. The Mulling Point store had a workforce of approximately 200 employees. This participant observation involved working 8.5 contracted hours per week as a shelfstacker. Work issues were also discussed with colleagues in the canteen before the shifts began and during the train commute to work. My co-workers, who acted as primary informants, were aware of my research and academic position.

Access to ShopPLC was gained through institutional gatekeepers: union officials and a manager at the Mulling Point store. Beyond Mulling Point, union officials provided access to workplaces and informants across London. To complement the interviews and observational 
data, a union official also provided copies of the official guides to 'flexible contracts' and 'labour matching' and the collective agreement. The use of gatekeepers meant that it was not possible to access the views of managers, as the gatekeepers could only provide access to workers. ${ }^{1}$ This is a weakness of the research design and means that some aspects of flexible scheduling, such as why managers used these practices and their perceived drawbacks, could not be investigated. This weakness will be returned to below. However, this pragmatism was necessary in order to gain adequate access to carry out a case study, which enabled research of the primary research interest - workers' perceptions and experiences of flexible scheduling and how this was influenced by a trade union.

The interview data in the form of audio files and observational and experiential notes were directly uploaded to Atlas.ti. Atlas.ti was then used to enable the systematic theoretical coding of the data in line with Vaughan's (1992) 'theory elaboration' coding approach. These initial codes were then focused down through axial coding (Charmaz, 2006).

\section{Findings}

With regards to the first research aim the formal scheduling procedures will be outlined before proceeding to provide an in-depth account of how scheduling actually operated in practice at ShopPLC. The collective agreement stipulated that the employment status of the hourly paid store ${ }^{2}$ workforce be limited to three forms - standard, temporary, and flexible. Standard workers were employed on contracts which guaranteed them fixed core hours (36.5 if full-time and no less than 4.5 hours if part-time) with overtime being voluntary. As page two of the Guide to Labour Matching Reviews explained:

'change is constant and is driven by many factors including new technology, customer demands, the economic climate and new business initiatives... [Labour matching] is the policy used to manage this constant change by making variations to employee's 
contracted hours... [and] identify where hours are needed in store.'

Therefore, if managers wished to alter workers' fixed core hours they had to follow this process which was enshrined in the collective agreement. Accordingly, managers had to establish a demonstrable business case for why a permanent alteration was necessary and this could not be based upon short-term fluctuations in demand. The Guide to Labour Matching Reviews stated that this business case must be established using the official labour matching review report which identified where the hours were needed in the store and provided the following example of genuine business case:

'There is a significant reduction in trade on a particular department where they can no longer support current hours, in these circumstances the Company should be able to demonstrate a legitimate business case.' (Guide to Labour Matching Reviews, p.4) Having made the business case for altering a worker's hours a 28-day consultation was to take place with the affected worker, during which managers had to take into consideration the individual's circumstances and explore all the options so as to reach a mutual agreement. If the individual's circumstances meant that they had what the collective agreement termed a ‘justifiable reason', i.e. primary caring responsibilities, transportation problems, a second job, health issues or pregnancy, then the worker could refuse to alter their hours. However, if the employee did not have a 'justifiable reason' and if management and the employee could not come to an agreement, then at the end of the consultation the worker would be issued with contractual notice (ranging from four to twelve weeks - depending upon length of service). At the end of this notice, the employee had to accept the change to their hours. If the worker felt that the labour matching procedure had not been correctly followed, they could seek remediation by raising a grievance. The outcome of these labour matching reviews could vary from small alterations to existing shift patterns, such as moving the shift 15 minutes or an hour later in the day, to more major ones such as moving a shift from a weekday to a 
weekend or modifying a daytime shift to be late at night. The most extreme alteration observed was the complete transformation of particular job role from days to nights.

Despite the official policy stipulating that such reviews were not to be carried out frequently or utilised in relation to short-term changes in demand, informants perceived them to be recurrent, apparently taking place between two and four times a year. Moreover, the review period could drag on for many months and in some cases lasted 12 months or more. They were in effect experienced by employees as a virtually constant process, with the outcome being hard to predict. For example, Sandra, a rep, described in detail during an interview how this procedure worked in reality:

'All of a sudden you will get called into an office, "right we need to have a chat with you" and you'll be all stressed about it... [But ] you won't hear nothing for two months and then three months and then four months... a year down the road they then say they have to do it again.'

ShopPLC had previously combined the temporal flexibility provided by labour matching with the numerical flexibility of temporary workers. Temporary workers were employed on fixed-term contracts of up to 12 weeks to cover peak periods of demand, such as Christmas. But this combination of temporal and numerical flexibility had proved inadequate. The Guide to Flexible Contracts explained that temporary staff brought additional costs in terms of recruitment and training and, in the case of online-only stores, agency fees. The Guide to Flexible Contracts also highlighted that labour matching reviews were timeconsuming, ill-suited to short-term changes in demand and not flexible enough to cope with recurring shifts in demand. Therefore, the year before the field work was undertaken, a new temporally flexible employment status was introduced. According to the Guide to Flexible Contracts, the aim of this new employment status was to increase flexibility by complementing the existing forms of employment. 
This new flexible employment status covered full-time and part-time employees in similar manners. Full-time workers were contracted for 36.5 hours, but these hours were not set. The hours could be scheduled at any time which the worker had indicated that they were available to work on a questionnaire administered during their interview (excluding Sundays which by law had to be voluntary). These workers had to provide at least 50 hours availability each week and their period of availability could then only be altered by the labour matching process outlined above. The worker's schedule was supposed to be drawn up at least four weeks in advance, but could be altered with as little as seven days' notice in 'exceptional situations.'

Flexible part-time workers had to fill in the same availability questionnaire during their interview and provide up to 48 hours per week of availability to work (although they would only work up to 36.5 hours). Workers were free to stipulate their preferred availability during their interview, but the Guide to Flexible Contracts explained that managers were to take into account whether the workers availability suited the company's needs before employing them. As such, providing greater availability increased the chances of being hired. Part-time flexible workers were contracted to work a minimum of 7.5 core hours per week and three hours per shift, although the Guide to Flexible Contracts made clear that ShopPLC believed that the ideal number was 10-16 hours per week. These workers could then be 'flexed' up with additional hours during their availability periods. These additional flexed hours were officially to equate to a maximum of $60 \%$ of the workers' core hours. For example, if employed for 10 core hours, their flexed hours should have been no more than six additional hours. These workers were to receive their additional hours at least seven days in advance, but in 'exceptional situations' could be given 24 hours' notice - but this was explicitly not to be the norm. These workers could also be asked to work overtime in addition to their flexedtime, without being given any notice. Both flex-time and overtime were paid at the standard 
rate.

In order to achieve the desired flexibility, the store's total contracted core hours needed to be below their base payroll budget. In this way, additional flexed hours could always be allocated to match demand and in busy periods these flexed hours could simply be further extended to meet increased demand. If workers refused to work at times when they were officially 'available', then in the first two instances they received a warning. After a third refusal, they would face disciplinary action, of which there were four stages before dismissal.

According to the Guide to Flexible Contracts, the implementation of this new flexible employment status was at the discretion of individual stores. However, it also made clear that a mixture of standard, temporary, and flexible workers were needed in order to respond to changes in demand while managing payroll budgets effectively. Flexible contracts were expected to limit the need for temporary workers to three peak trading periods (Easter, summer, and Christmas) and even during these periods the payroll costs of temporary workers would be restricted to around $10 \%$ of the normal payroll. For new stores, the Guide to Flexible Contracts explained that the ideal model was to reduce core contracted hours to $80 \%$ of the payroll costs so that the remaining $20 \%$ could be allocated to additional hours in order to match short-term changes in demand. This would require approximately $45 \%$ of staff to be on flexible contracts. This was also considered to be the ideal model for existing stores to move towards. The transition towards this ideal was gradual for existing staff could not be transferred to flexible contracts unless they applied for a new job role. However, by January 2013 the union rep guide noted that flexible contracts were becoming increasingly common. Despite plenty of evidence of part-time flexible contracts, there was none for full-time flexible contracts, presumably because part-time flexible workers presented greater potential for flexibility through the combination of flexed-time and overtime - see below. Although the sampling was not randomised, this is suggestive that the use of flexible part-time workers 
may be more common at ShopPLC, at least, in the stores studied. Consequently, the discussion below regarding workers employed on flexible contracts is limited to this parttime flexible work.

Part-time contracts and flexible contracts operated as complementary forms of 'short hours contracts' (SHC). Flexible contracts required the working of compulsory 'flexed-time' while standard part-time workers could only be offered voluntary overtime, paid at the standard rate for all workers employed since 2005. However, a store's usage of flexed-time and over-time were meant to be roughly equivalent. These necessitated that both part-time and flexible workers were hired for only minimal core contractual hours to ensure demand could be met through fluctuating additional hours. A common theme of the interviews was the similar disjuncture between contracted hours and the additional hours that both part-time and flexible employees actually worked.

Additional hours were an important feature of the workplace with standard part-time and flexible workers on average working 36 hours a week but being contracted for an average of just nine hours a week. Although traditional part-time workers were not contractually obliged to accept additional hours, in reality it was unlikely that those employed on SHC would refuse additional hours, despite only being paid at the same rate as core hours. The nature of low pay and low hours contracts meant that these workers often had a material need for additional hours. For example, frequently all of my team at Mulling Point worked overtime despite complaining how hard it was to work a nine hour shift and that their bodies were aching. Moreover, this precarious situation of not having enough hours to make ends meet was heightened by a perception that refusal to work overtime would result in overtime not being offered in the future. Derek, a union rep, explained this situation lucidly during an interview:

'People will do their utmost to do the extra hours and will allow themselves to be 
bullied into working days they don't really want to work or shifts that they don't really want to work. A lot of them are actually struggling to get childcare in place and things because they are terrified of not getting any more shifts and being stuck with this threeand-a-half or seven hours a week, which they've gotta live on... so I've known managers to say “look if you don't do the shift tomorrow, I won't offer you any more.' The other major difference was that unlike overtime, flexed-time was meant to require at least 24 hours' notice but this contractual protection was also perceived to be disregarded. As Mike, a union official, explained during an interview:

'They don't use the rules and try and take advantage "you will come in tomorrow.", ShopPLC's policy that additional flexed hours should only constitute $60 \%$ of core hours also made little difference as it could be bypassed through the use of traditional overtime. This meant that overtime/flexed-time could constitute three-quarters of a worker's total weekly hours. This was, however, well below the most extreme example. Jimmy, a union rep, stated that workers were being contracted for less than four hours a week but typically working 36 hours, meaning that overtime/flexed-time was increasing their hours nine fold.

Given that these contractual protections and company policies were habitually disregarded by managers, from the workers' perspective, the differences between being employed on a standard part-time short hours contract and a flexible short hours contract were minor. Both were understood by workers as entailing little notice of unpredictable and irregular additional hours and the disappearance of un-contracted hours which they had become accustomed to working.

In terms of maximising scheduling flexibility, overtime and flexed-time had contrasting advantages and drawbacks and this made them highly complementary, which is why ShopPLC aimed to have them utilised in equal proportions. The main advantage of overtime was that workers did not have to be given any notice, thus workers could be offered 
overtime with even less notice than the 24 hours contractually required for flexed-time, providing the flexibility to respond to real-time changes in demand. For example, it was observed that it was common for members of my team of shelf-stackers at Mulling Point to be offered overtime for the following morning during our evening shifts or even extend the shift that was currently being worked. In an illustrative example, Rio was asked to extend his shift as he was putting his coat on to go home. The obvious disadvantage of overtime was that workers had discretion as to whether they accepted or rejected the additional hours, thus overtime had the potential, at least, to leave demand unmet. The advantage of flexed-time was that workers could not decline additional hours if given 24 hours' notice, so demand was guaranteed to be met but the drawback was that managers had to anticipate and plan for the increased demand at least 24 hours in advance. This added a level of complexity to scheduling, which increased with the number of workers employed in this way. Managers had to plan for changes in demand, rather than simply adjusting schedules through allocating overtime in real time as needed.

In sum working time at ShopPLC was found to be highly flexible and this flexibility to be driven be changes in demand. Firm flexibility was not confined to atypical forms of employment and was evident across employment statuses. Standard core hours were altered through labour matching, while the use of SHC meant that highly variable additional hours were an important feature of part-time and flexible employment. New temporally flexible employment practices, flexi-contracts, flexed-time and SHC, were introduced as means of reducing reliance upon the costly numerical flexibility provided by temporary and agency workers. Under the new flexible regulation of working time, the aim was that temporary workers would only be required during the three peak trading periods and even then would only make up $10 \%$ of the workforce. 
Flexible scheduling and job quality: 'a two way process?'

The second research aim was to examine how flexible scheduling affects perceptions of job quality. According to the collective agreement there were a number of provisions which might be expected to provide workers with influence over labour matching changes to core hours and the ability to delay the implementation of any changes by between two to four months. Additionally, the Guide to Flexible Contracts emphasised that the flexibility of the flexible contracts was 'two way,' enabling both MCFS and WCFS, as workers could request not to work reasonable hours which fell during their availability if they had not yet been scheduled and this was claimed to provide workers with schedules which:

'suit people's lives... allowing staff in our stores to work hours that can be flexible enough to meet their individual needs.'

It was expected that with these policies in place flexible scheduling would not be overly negative for job quality. However, this was not the case with flexible scheduling, nonetheless, found to diminishing workers' WLB by impairing their ability to plan their time and consequently impacting negatively upon family life and childcare responsibilities. Sara a union rep provided a characteristic experience:

'Now that Paul [another ShopPLC worker] is living with me, we've set aside Saturday as a day to do something - me, Paul and my son - as a family... she [Sara's manager] now wants me to work Saturdays... it's all up in the air.'

Asim a union rep explained:

'They balance their work life with their family life i.e. dropping their kids off or having carers and when suddenly the business is like "you have to change your hours again" it affects them, it affects them immensely because they have to start it all over again, they have to balance their family life because they don't want to lose their job, so they have to make a lot of sacrifices.' 
Not all time is equal. Even small changes to schedules had big repercussions on childcare. Moreover, primary childcare was not the only type of caring impacted. Low income families could not afford professional childcare and therefore relied on family members such as grandparents. With around 20\% of ShopPLC's workforce being over fifty, providing childcare for grandchildren was a concern of many workers. Yet labour matching policies only considered primary care as a 'justifiable reason' for not changing hours.

Inability to plan one's life also acted as a barrier to undertaking social activities with the unpredictable nature of schedules causing workers to experience their lives as being in disarray, Susan's (ShopPLC, worker) experience was indicative of this:

'You plan something and then they say 'oh can you come in and do something different' and you feel compelled to do it. So you're changing all everything around.' The potential impact of dramatic alterations to schedules could have a serious impact upon workers' wellbeing as Colin described:

'I had to change hours, or accept another position, or try another store... To change to nights would be too much upheaval in my life... I felt really sick, it just hit me, it hit all of us ... they said I could tweak it... maybe half an hour.'

When workers did not experience MCFS negatively it was because they had more flexible non-work lives, such as few caring responsibilities or family commitments, and thus MCFS presented less of a WLB issue. Toby a young male worker without dependents explained that: 'I'm quite flexible and easy going so unless it was something big time bad it wouldn't really bother me.'

\section{Union impact on flexible scheduling}

The third research aim was to explore the union's (in)ability to influence flexible scheduling so as to improve job quality. As outlined above, flexible scheduling at ShopPLC was 
officially to be carried out according to a collective 'partnership' agreement which in theory placed a number of constraints on MCFS and provided two potential ways in which any changes could be resisted. Firstly, by arguing that a business case had not been made and thus no consultation could take place. Secondly, by making a case that there existed a 'justifiable reason' for not altering their hours. It was thus possible for workers to resist changes through enforcement of this procedure if they had the support of a well-informed union rep involved from the beginning of the process. But more commonly informants explained how in practice management ignored these policies with impunity.

Managers were widely perceived by the informants to not be holding proper consultations in which they were willing to listen to workers' concerns and come to a compromise. Union reps and workers recounted how managers would instead intimidate workers into changing their hours to such an extent that the workers were afraid that they would be dismissed or lose their job role if they were not compliant. Susan explained during an interview how this fear formed a barrier to the union's influence:

'People do feel compelled to do it and don't really have a choice in it, if they still wanna a job because it's that whole canopy of 'you're lucky to have a job'... That's the biggest thing, people go to them [the union] and then they get half way through the process and they think 'hang on a moment I could lose my job through this, I don't want to do this anymore', they sort of get a little bit scared.'

Another worker, Rosie, elaborated during an interview on how managers' subtle threats heighten such feelings:

'You get told that there are plenty of people out there who need jobs, so it's more bribing than anything else.'

Asim, a union rep, made it clear during an interview that, in some cases, this fear was achieved less subtly and clearly in contradiction to ShopPLC's policies: 
'People have been told, wrongly, that they can be sacked for it if they don't change their hours.'

Furthermore, while the company policy stated that labour matching reviews should not result in reduced core hours, workers would 'voluntarily' reduce their hours in order to remain in their current department and job role. As Neil (a union rep) explained during an interview:

'It was all these shifts cobbled together and it wasn't a job but what it allowed them to do was cut hours... so it's been a way of cutting costs, people have cut their hours because they want to stay in their department.'

The selection of workers for schedule changes was not transparent and was believed to target timid workers who were unlikely to voice their dissatisfaction. Hence one of the union officials explained that very few reviews ever went to contractual notice despite workers dissatisfaction. In terms of flexed-time, there was also very little evidence that the trade union was effective at increasing worker influence over schedules through the enforcement of the provisions regarding the ratio and notice of additional hours.

The ability of managers to ignore company policies enshrined in a collective agreement, and to pressure workers to accept changes to their hours, was made possible by the relationship between the union and company being structured in such a way that workers' collective voice was limited. The only institutionalised communication channel through which collective dissatisfaction could be voiced was via consultation committees. These consultation committees were infrequent, detached, and distanced from the workplace, thus they reduced the ability of union reps to effectively and powerfully transmit workers' collective voice and their agenda was dominated by ShopPLC. As Lee, a union official, explained during an interview:

'The way ShopPLC and the union do our negotiations is through the consultation committee processes... and quite a lot of these things [issues with MCFS] are negotiated 
at the area consultation stage and then pushed down to the stores. It's, you know, if I'm completely honest, it feels like one-way traffic at times from ShopPLC.'

In reality the only mechanism available for raising dissatisfaction, even those of a collective nature, was the individual grievance procedure. This meant that workers' collective problems ended up being individualised as was the role of the union. It was observed, for instance, how at a rep team meeting the presumption that managers would only deem a grievance legitimate if raised by the individual affected prevented the store's reps from attempting a collective response to the labour matching review process.

Nevertheless, the union reps were generally perceived as having the potential to provide important support with the grievance and disciplinary procedures. This was also true of grievances concerning scheduling and some workers and reps gave this as a central reason why workers joined the union. For example, William, a worker, gave this as a reason why he had joined the union:

'If I didn't want to do it [change his hours]... I know I'd have someone on my side to help me with that.'

While another worker, James, gave this as the one of the reason he had joined the union and suggested it was why his co-workers should also join:

'You need unions for disciplin[ari]es or if you're just not happy with something they [ShopPLC] are trying to do, [like] changing your hours - you can go to the union and they can try and help you. And I would say everyone should join the union as it's a good thing to have behind you.'

However, with regards to flexi-contracts not all union reps agreed that they facilitated recruitment for they argued that, in spite of these workers having a greater need of union support, they were also unwilling to commit to making regular dues payments when they were unsure of their income week-on-week. 
Despite the perception that union reps could provide effective support with grievances, a major barrier to their ability to do so with regards to scheduling was the fact that workers did not involve them at an early stage and sometimes even after they had agreed to the changes. Due to the intimidation outlined above, workers often felt vulnerable, victimised and afraid of losing their job and were thus hesitant to pursue a grievance in regards to scheduling. Worker informants recognised that they were highly dependent upon ShopPLC for their livelihoods and had little confidence that there were labour market alternatives available to them. Indeed, this feeling of dependence was frequently given in the interviews as a reason for the acceptance of poor working conditions. Mark, a union rep, explained this forcefully during a rep team meeting in which reps discussed the potential for labour matching grievances:

'The weak ones are ridden over roughshod and as soon as we come to them and say "well you have to stand up, we'll be with you but you have to stand up," they will fade away; they are dead scared, absolutely petrified of standing up to management.

Rather than MCFS being challenged by the union, in some cases, the union actually eased its operation by reducing worker resistance. For the collective voice function of reps could be distorted by their acceptance and internalisation of ShopPLC's justification for MCFS. Reps frequently legitimised MCFS as being a right of managers. For example, Jimmy, a rep, explained during an interview how he dealt with the discontent caused by labour matching:

'Basically what you do is reassure them, "yes we have looked at it, no they are not breaking any laws, they have the right to move you around the business.'

MCFS was also commonly legitimated through a 'needs of the business' idiom. An example of this idiom is provided by Asim, a union rep, who saw his role during labour matching reviews as eliciting a mind-set amongst workers in which they would be willing to accept 
changes to their schedules:

'We have to understand the needs of the business, if the needs of the business dictates that certain people have to work certain hours and certain days, then as a unit we need to understand that... If they haven't got legitimate concerns or legitimate reasons why they can't change their hours then the manager will expect and the company and the store will expect them to change their hours, so I will try and get them in that mind-set.'

One rep, Toby, had completely internalised the employer's logic that what was legitimate was that which benefited the company's bottom line, and not the needs of the workers he was elected to represent:

'Labour matching - there is obviously a business need for it and the union wants ShopPLC and supermarkets to do well for members and things like that and employment.'

This rep's level of identification with the interests of his employer over the interests of his members was an extreme example. But it is, nevertheless, revealing of the internal conflicts which other reps faced, for they commonly explained their role as being to 'balance the needs of the business with the needs of the worker.'

\section{Discussion and conclusions}

The three aims of this article have been: to provide an in-depth exploration of temporal flexibility and the degree to which flexible scheduling is manager or worker controlled, ascertain how flexible scheduling in practice affects perceptions of job quality, principally in terms of WLB, and investigate the ability of a trade union to improve perceptions regarding this element of job quality. With regards to these three aims the article makes four key contributions which will now be discussed with relation to the extant literature.

Firstly, temporal flexibility at ShopPLC was achieved in practice through MCFS with 
little evidence of WCFS. Flexible scheduling was being pursued in order to lower costs through the better matching of supply and demand and thus required managerial control of this flexibility. This suggests the need to be sceptical of accounts which do not distinguish between WCFS and MCFS (e.g. CIPD, 2013; 2015; Pennycook et al., 2013). For example, research by the CIPD (2013) into ZHCs, widely seen as constituting an extreme form of MCFS (Rubery et al., 2005), surprisingly found that around half of such workers were satisfied with being employed in this way. Yet this finding can be partially explained by the fact that it is the aggregated result drawn from a highly heterogeneous sample. As Lambert et al. (2012) point out low-end hourly-paid workers tend to have have far less ability to access WCFS than their high-end salaried managerial and professional counterparts. Yet the CIPD's (2013) sample included both high paid individuals (42\% earned $£ 25,000$ or more a year, and of these $14 \%$ earned $£ 45,000$ or more a year) and low-paid workers ( $28 \%$ earned less that $£ 15000$ per year). The same number also had a lot of choice over the number of hours they worked. This may indicate that the sample includes both high-end and low-end workers with highly divergent abilities to control flexible scheduling. The aggregation of workers with contrasting experiences of flexible scheduling in this way is questionable. Future research must pay greater attention to the experiences of flexible scheduling and the likely ability of workers to control it. Care is necessary to avoid the WCFS of high-end workers being presented as evidence of the positives of flexible scheduling for low-end workers; this study demonstrates low-end workers are unlikely to share the same level of control.

Manager-controlled flexible scheduling was detrimental to nearly all workers' perceptions of job quality. Only two workers indicated that job quality was not adversely affected by MCFS (both of these workers had few non-work commitments). This supports the findings of previous research that manager-controlled flexible scheduling is damaging to job quality (Carré et al., 2010; Kalleberg, 2011). Specifically, it diminished workers'WLB by 
impairing their ability to plan their time and consequently impacted negatively upon family life. This is similar to the findings of several other studies, for example Chung et al. (2007); Fagan and Burchell (2002); Goudswaard et al. (2012); Riedmann et al. (2010). Studies that have found no adverse effects of flexibility on WLB (e.g. CIPD, 2013; 2015; Pennycook et al., 2013) can be explained by a conceptual confusion between MCFS and WCFS, in other words they combined experiences of WCFS with experiences of MCFS. Any policy discussions that do not distinguish between WCFS with MCFS are likely to be highly misleading. For example, the UK Government Minister for Work and Pensions has suggested that ZHCs enable workers to 'flex their work' and are therefore positive for WLB (Stone, 2015). Yet it seems highly implausible that all, or even most, workers employed in this way benefit from WCFS and (as the results of this study demonstrate) MCFS is clearly detrimental for WLB.

Secondly, Atkinson (1984) argues that flexible firms maintain a core group of employees who are full-time, have low turn-over and high job security. Matisik and Hill (1998: 689) suggest that the non-core 'contingent workforce consists of independent contractors; individuals brought in through employment agencies; on-call or day labor; and workers on site whose services are provided by contract firms.' Therefore, according to Atkinson (1984) and Matusik and Hill (1998) the temporally flexible workers at ShopPLC should be understood as constituting part of the core workforce. This is because they are central to to ShopPLC's core operations of stocking and selling goods, with this importance being reflected by their permanent contracts, employment protections and loyalty incentives such as defined benefit pensions. In fact, 90\% of ShopPLC's workforce had more than one year's service, indicating that they were at least partially shielded from the external labour market. Yet temporal flexibility at ShopPLC was found to be experienced across employment statuses with hourly-paid full-time, part-time, and flexible workers all facing MCFS through 
either labour matching of core hours and/or additional overtime and flexed-time. Moreover, the purpose of increasing temporal flexibility was to reduce the need for numerically flexible temporary and agency workers who most closely resemble the contingent peripheral workers in the flexible firm model. This supports the finding of Rubery et al. (2005) that flexible regulation of working time is being increasingly generalised across employment statuses, reducing the need for workforce segmentation.

The findings of this study suggest that the flexible firm model requires significant revision if it is to remain relevant in an increasingly temporally flexible age. The finding of temporal flexibility across employment statuses necessitates that the model be adapted in two significant ways. First, the core workforce needs to be limited to managers and head office staff, as they are the only employees who do not experience temporal flexibility with employees such as these having long hours and rigid schedules (Lambert et al. 2012). Elaborating the flexible firm model in this way would, however, leave the 'core' representing less than five percent of the workforce. Second, the barriers between Atkinson's (1984) first and second peripheral groups would have to be conceptually broken down to account for flexibility being mainly provided temporally (rather than numerically) by all peripheral workers. Numerical flexibility being restricted to cover occasional peak trading times and even then restricted to around ten percent of the total workforce. Revising the flexible firm model in this way, so that nearly all the workforce is located within one temporally flexible periphery, inevitability brings into question the continued utility of the model.

To a degree the findings parallel those of Ackroyd and Procter (1998) in highlighting that flexibility is not necessarily achieved via a division between a highly skilled core and low skilled periphery. However, the findings differ from their 'new flexible firm model' in highlighting the importance of generalised temporal flexibility as opposed to numerical flexibility. Future research is needed to further elucidate the continued relevance of the 
flexible firm model, while an important policy implication of this finding is that discussion of MCFS should not be confined to atypical employment statuses such as 'zero hours employment.'

Thirdly, the union was found to be largely ineffective at ameliorating MCFS and thus improving job quality. This contrasts with previous research in Continental Europe which has found unions to have a positive effect on flexible scheduling (Goudswaard et al., 2012; Carré et al. 2010). This finding then is surprising, especially given the union's relatively high density (above 60\%). It can best be explained with reference to Kelly’s (2004) 'employerdominated' or 'labour parity' typology of partnership agreements. Kelly argues that the balance of power determines which side gains most from partnership agreements. The findings above suggest that the agreement at ShopPLC was an employer-dominant agreement. The fact that ShopPLC had seriously considered derecognition before opting for a partnership and the fact that the union was reliant upon ShopPLC for the major part of its membership adds credence to this view.

This raises the question of why a union with relatively high density did not challenge such an employer-dominant agreement? Furthermore, why were workers themselves so reluctant to press for more control over scheduling? As argued above, workers' power is comprised not only of associational power but also structural economic power. Therefore, while the union's members had significant associational power (owing to the union having a membership of hundreds of thousands who were relatively concentrated in ShopPLC), this was not sufficient to compensate for their lack of structural economic power. Workers lacked structural economic power due to high levels of underemployment. In addition, their jobs did not require scarce skills. Most workers also lacked adequate savings to use as an alternative to paid work. Moreover, these retail workers did not occupy positions of strategic importance in the social organisation of labour, either with regard to their specific employer's activities or 
in terms of the more general social division of labour across the economy. Functional flexibility meant there was very little specialisation in terms of job roles. Whereas strikes by energy workers could cause major disruption, strikes by these workers at ShopPLC could only have minor implications for wider economic activity. The limited amount of structural economic power which accrues to retail workers was demonstrated when a five-month strike by fifty-nine thousand supermarket workers at 850 stores in Southern California in 2003 was largely ineffective (Lichtenstein, 2009).

Additionally, the fact that the collective agreement was at the company level and the retail sector highly competitive further limited the structural economic power of the union. As noted above UK unions lack the legal and institutional supports of their Continental cousins. This lack of both institutional and structural economic power explains why the union acquiesced to ShopPLC's flexible scheduling demands. This supports the view of Hoque et al. (2014) that union impact on job quality will be dependent upon the union having sufficient bargaining strength to compel managers to respond constructively to workers' collective voice.

Fourthly, the role of union reps in legitimising MCFS and encouraging workers not to challenge it highlights that union reps do not represent a simple one-way transmission of neutral information from workers to managers. Rather, they also transmit information from managers to workers and what they convey and the manner in which it is conveyed will be shaped by the wider political and symbolic practices which they encounter (Gallie, 1978; Hyman, 1979). This finding represents a reminder that union reps do not simply act as delegates who reflect the views of their members. They can also act largely on their own judgment, both initiating and supressing issues and deciding how issues are dealt with and installing in members particular priorities and views (Batstone et al., 1977).

Kelly (1998) elucidates how different actors within the workplace attempt to influence 
the understanding of workplace issues through framing them in particular ways. Action on workplace issues requires that they come to be understood by workers as being both an injustice and as being avoidable. The tendency of reps to frame MCFS as both justified and unavoidable owing to the 'needs of the business' idiom provides an explanation as to why workers did not try to challenge MCFS. This finding adds weight to the assertion by Kelly (2004: 269) that 'partnership agreements contribute to union weakness by reinforcing an ideology of common interests.' Future research must continue to seriously reflect on the effect of partnerships agreements on union reps' values.

There are, however, a number of limitations to this present research which it is necessary to highlight. Firstly, it was not possible to include managers in the research design. Although documentary evidence provides the formal rationale for the adoption of these policies, the intentions of managers in practice cannot be understood from the data. It is impossible for this study to infer the practical reasons why managers make use of MCFS and, from their perspective, the positives and negatives of doing so. Research is needed to investigate the views of managers vis-à-vis why such practices are used and their awareness of the problems. Secondly, the findings are based upon only one context-dependent case study in a single sector. The insights gained from this study will, however, inform the design of future quantitative research which will be able to test the generalisability of the findings.

\section{Acknowledgments}

I would like to thank Brendan Burchell and William Brown for their support and valuable suggestions. I would also like to thank the editor Kim Hoque and the three anonymous referees for their numerous constructive criticisms and recommendations.

\section{Funding}


This research was supported by funding from the Economic and Social Research Council (grant numbers ES/I017011/1 and ES/I901957/1).

\section{Notes}

1. ShopPLC at corporate level did not respond to requests for interviews with corporate and store-level managers.

2. This excludes online only 'stores' which it was not possible to access. Flexible contracts were also introduced for these stores, with the rationale stated in the Guide to Flexible Contracts being to eliminate the need for agency workers and the associated agency fees. Consequently, these flexible contracts consisted of 3.75 core hours and could be increased by up to 3.75 hours with just two hours' notice.

\section{References}

Ackroyd S and Procter S (1998) British Manufacturing Organization and Workplace Industrial Relations: Some Attributes of the New Flexible Firm. British Journal of Industrial Relations 36(2): 163-183.

Atkinson J (1984) Manpower strategies for flexible organizations. Personnel Management 16(8): 28-31.

Badigannavar V and Kelly J (2011) Partnership and organizing: An empirical assessment of two contrasting approaches to union revitalization in the UK. Economic and Industrial Democracy 32(1): 5-27.

Batstone E, Boraston I and Frenkel S (1977) Shop stewards in action: the organization of workplace conflict and accommodation. Oxford: Wiley-Blackwell.

BIS [Department of Business Skills and Innovation] (2013) Consultation: Zero Hours Employment Contracts. London: Department of Business Skills and Innovation. 
BIS [Department for Business, Innovation and Skills] (2014) Trade Union Membership 2013: Statistical Bulletin. London: Department of Business Skills and Innovation.

Brown W, Bryson A, Forth J and Whitfield K (Eds) (2009) The Evolution of the Modern Workplace. Cambridge: Cambridge University Press.

Brown W, Deakin S, Nash D and Oxenbridge S (2000) The Employment Contract: From Collective Procedures to Individual Rights. British Journal of Industrial Relations 38(4): 611-629.

Bryman A (2008) Social Research Methods. Oxford: Oxford University Press.

Burawoy M (1979) Manufacturing consent: Changes in the labor process under monopoly capitalism. Chicago: University Of Chicago Press.

Carré F, Tilly C, van Klaveren M and Voss-Dahm D (2010) Retail Jobs in a Comparative Perspective. In Gautié J and Schmitt J (Eds.) Low-Wage Work in the Wealthy World. New York: Russell Sage Foundation, 211-268.

Charmaz K (2006) Constructing Grounded Theory: A Practical Guide Through Qualitative Analysis. London: SAGE.

Chung H, Kerkhofs M and Ester P (2007) Working time flexibility in European companies. Dublin: Eurofound.

CIPD (2013) Zero Hours Contracts: myth and reality. London: CIPD.

CIPD (2015) Zero-hours and short-hours contracts in the UK: employer and employee perspectives. London CIPD.

Darlington R (2010) The state of workplace union reps' organization in Britain today. Capital and Class 34(1):126-135.

Edwards P (2014) Rigor and Limitations of Case Study Research in Employment Relations. Keynote Lecture at British Universities Industrial Relations Association $\mathrm{PhD}$ Symposium, Leeds, UK. 
Fagan C and Burchell B (2002) Gender, jobs and working conditions in the European Union. Dublin: Eurofound.

Findlay P, Kalleberg A.L amd Warhurst C (2013) The challenge of job quality. Human Relations 66(4): 441-451.

Gallie D (1978) In Search of the New Working Class: Automation and Social Integration Within the Capitalist Enterprise. Cambridge: Cambridge University Press.

Glucksmann M [aka Cavendish R] (2009) Women on the Line. London: Routledge.

Goudswaard A, Dhondt S, Vergeer R and Oeij P (2012) Organisation of working time: Implications for productivity and working conditions - overview report. Dublin: Eurofound.

Gregory A and Milner S (2009) Trade unions and work-life balance: changing times in France and the UK? British Journal of Industrial Relations 47(1): 122-146

Gumbrell-McCormick R and Hyman R (2013) Trade Unions in Western Europe: Hard Times, Hard Choices. Oxford: Oxford University Press.

Henly J.R and Lambert S.J (2005) Nonstandard work and child care needs of low income parents. In Bianchi S.M, Casper L.M, King R (Eds.) Work, family, health \& well-being. Mahwah NJ: Lawrence Erlbaum Associates.

Henly J.R, Shaefer H.L and Waxman R.E (2006) Non-standard work schedules: Employerand employee-driven flexibility in retail jobs. Social Service Review 80(4):609-34.

Holman D (2013a) Job types and job quality in Europe. Human Relations 66(4): 475- 502.

Holman D (2013b) An explanation of cross-national variation in call centre job quality using institutional theory. Work, Employment and Society 27(1): 21-38.

Hoque K, Earls J, Conway N and Bacon N (2014) Union representation, collective voice and job quality: an analysis of a survey of union members in the UK finance sector. Economic and Industrial Democracy Epub ahead of print 17 December 2014. DOI: 
$10.1177 / 0143831 X 14555707$.

Hyman J, Scholarios D and Baldry C (2005) Getting on or getting by? Employee flexibility and coping strategies for home and work. Work, Employment and Society 19(4): 705725.

Hyman R (1979) The Politics of Workplace Trade Unionism Recent Tendencies and Some Problems for Theory. Capital and Class 3(2): 54-67.

Kalleberg A.L (2011) Good Jobs, Bad Jobs: The Rise of Polarized and Precarious Employment Systems in the United States, 1970s-2000s. New York: Russell Sage. Katz H.C (1993) The Decentralization of Collective Bargaining: A Literature Review and Comparative Analysis. Industrial and Labor Relations Review 47(1): 3-22.

Kelly J (1998) Rethinking Industrial Relations: Mobilisation, Collectivism and Long Waves. London: Routledge.

Kelly J (2004) Social partnership agreements in Britain: Labour Co-operation and compliance. Industrial Relations 43(1): 267-292.

Lambert S.J (2008) Passing the buck: Labor flexibility practices that transfer risk onto hourly workers. Human Relations 61(9): 1203-1227.

Lambert S.J, Haley-Lock A and Henly J.R (2012). Schedule flexibility in hourly jobs: unanticipated consequences and promising directions. Community, Work \& Family. 15(3): 293-315.

Lichtenstein, N. (2009) The Retail Revolution: How Wal-Mart Created a Brave New World of Business. New York: Picador.

Matusik S and Hill C.W.L (1998) The Utilization of Contingent Work, Knowledge Creation, and Competitive Advantage. The Academy of Management Review 23(4): 680-697.

ONS (2015) Official Labour Market Statistics: Unemployed Great Britain. Available at: http://www.nomisweb.co.uk/reports/lmp/gor/2092957698/subreports/nrhi time series/r 
eport.aspx (accessed 1 August 2015).

Pennycook M, Cory G and Alakeson V (2013) A Matter of Time: The rise of zero-hours contracts. London: Resolution Foundation.

Riedmann A, van Gyes G, Roman A, Kerkhofs M and Bechmann S (2010) European Company Survey 2009 - overview report. Dublin: Eurofound.

Roy D (1959) "“Banana Time”: Job satisfaction and informal interaction. Human Organization 18(4): 158-168.

Rubery J, Ward K, Grimshaw D and Beynon H (2005) Working Time, Industrial Relations and the Employment Relationship. Time and Society 14(1): 89-110.

Sallaz J.J (2015) Permanent Pedagogy: How Post-Fordist Firms Generate Effort but Not Consent. Work and Occupations 42(1): 3-34.

Stone J (2015) Zero-hours contracts should be renamed 'flexible-hours contracts' and are good for your work-life balance, Iain Duncan Smith says. Independent 17 April. Available at: www.independent.co.uk/news/uk/politics/zero-hours-contracts-should-be$\underline{\text { renamed-flexible-hours-contracts-and-are-good-for-your-work-life-10184186.html }}$ (accessed 15 January 2016).

Vaughan D (1992) Theory Elaboration: The Heuristics of Case Analysis. In Ragin H and Becker S (Eds.) What Is a Case? Exploring the Foundations of Social Inquiry. Cambridge: Cambridge University Press, 173-202.

Wright C and Brown W (2013) The effectiveness of socially sustainable sourcing mechanisms: Assessing the prospects of a new form of joint regulation Industrial Relations Journal 44(1): 20-37.

Wright E.O (2000) Working-Class Power, Capitalist-Class Interests, and Class Compromise. American Journal of Sociology 105(4): 957-1002.

Zeytinoglu, I.U, Lillevik W, Seaton B and Moruz J (2004) Part-time and casual work in retail 
trade: Stress and other factors affecting the workplace. Relations Industrielles 59(3): 516-544.

Alex J. Wood is a Researcher at the Oxford Internet Institute, University of Oxford. His research focuses on the changing nature of employment relations and labour markets. He is currently researching how online labour markets and virtual employment relations are transforming world the work. His previous research focused on the changing nature of flexible and insecure forms of work such as zero hour contracts in the UK and US. He also has a long standing interest in the relationships between industrial relations, union renewal and emerging forms of workplace representation and new patterns of class and inequality. His research has appeared in Industrial Relations Journal and CritCom. [Email: alex.wood@oii.ox.ac.uk]

\section{Corresponding author:}

Dr Alex J. Wood

http://orcid.org/0000-0002-3984-7984

Oxford Internet Institute

University of Oxford

1 St Giles

Oxford

OX1 3JS

UK

alex.wood@oii.ox.ac.uk 